\title{
Evaluation of pharmacokinetic and pharmacodynamic parameters of meropenem in critically ill patients with acute kidney disease
}

\author{
Rezvan Hassanpour ${ }^{1}$. Shadi Ziaie ${ }^{1}$ - Farzad Kobarfard ${ }^{2} \cdot$ Mehran Kouchek $^{3}$ - Mirmohammad Miri ${ }^{3}$. \\ Azadeh Ahmadi Koomleh ${ }^{4}$. Seyedpouzhia Shojaei ${ }^{3}$ - Sara Salarian ${ }^{3}$ - Elham Pourheidar ${ }^{1}$. Fatemeh Nezarat ${ }^{5}$. \\ Mohammad Sistanizad ${ }^{1,6}$ (i)
}

Received: 3 July 2020 / Accepted: 2 December 2020 / Published online: 6 January 2021

(C) The Author(s), under exclusive licence to Springer-Verlag GmbH, DE part of Springer Nature 2021

\begin{abstract}
Purpose No study has been evaluated pharmacokinetic (PK) and pharmacodynamic (PD) properties of $\beta$-lactam antibiotics in patients with acute kidney injury (AKI), not requiring renal replacement therapy (RRT). We evaluated the time that plasma concentrations remain above four times the MIC ( $\mathrm{ft}>4 \mathrm{MIC}$ ) and PK parameters of meropenem in this population.

Methods In this prospective, randomized clinical trial (RCT), all patients received standard dose ( $3 \mathrm{~g}$ daily) of meropenem for $48 \mathrm{~h}$, then randomly allocated in standard or adjusted groups. The standard group received meropenem without dose adjustment. In the adjusted group, the meropenem dose was adjusted based on the Cockcroft-Gault(C-G) equation. Meropenem concentrations were measured at the peak and trough times on the 2nd and 5th days of the study.

Results On the 2 nd day of the study, 3 out of $10(30 \%)$ of patients attained the PD target ( $\geq 80 \% \mathrm{ft}>4 \mathrm{MIC})$. In the 5 th day of the study, the PD target was attained in 2 out of $10(20 \%)$ and 1 out of $5(20 \%)$ of patients who received standard and adjusted doses of meropenem, respectively $(p=1)$. In all samples, increased volume of distribution (Vd) (median; IQR) (46.04; 23.06-103.18 L), terminal half-life $(\mathrm{T} 1 / 2)(4.51 ; 2.67-8.88 \mathrm{~h})$ and decreased clearance $(6.52 ; 4.43-10.16 \mathrm{~L} / \mathrm{h})$ have been shown.

Conclusion In critically ill patients with AKI, who not receive RRT, standard doses, and adjusted according to renal function of meropenem failed to achieve PD target of $\geq 80 \% \mathrm{ft}>4 \mathrm{MIC}$. Higher doses are required for this target.

Retrospectively registered The study protocol with registered retrospectively and approved on January 19, 2019, with the number of IRCT20160412027346N5.
\end{abstract}

Keywords Acute kidney injury $\cdot$ Pharmacokinetic $\cdot$ Pharmacodynamic $\cdot$ Meropenem

Mohammad Sistanizad

sistanizadm@sbmu.ac.ir

1 Department of Clinical Pharmacy, Faculty of Pharmacy, Shahid Beheshti University of Medical Sciences, Tehran, Iran

2 Department of Medicinal Chemistry, Faculty of Pharmacy, Shahid Beheshti University of Medical Sciences, Tehran, Iran

3 Department of Critical Care Medicine, Imam Hossein Medical and Educational Center, Shahid Beheshti University of Medical Sciences, Tehran, Iran

4 Department of Nephrology, Imam Hossein Medical and Educational Center, Shahid Beheshti University of Medical Sciences, Tehran, Iran

5 Student Research Committee, Department of Clinical Pharmacy, Faculty of Pharmacy, Shahid Beheshti University of Medical Sciences, Tehran, Iran

6 Prevention of Cardiovascular Disease Research Center, Imam Hossein Medical and Educational Center, Shahid Beheshti University of Medical Sciences, Tehran, Iran

\section{Introduction}

Acute kidney injury (AKI) is one of the common problems in critically ill patients, especially subjects with sepsis [1]. In this phenomenon, pathological factors alter pharmacokinetic (PK) and pharmacodynamic (PD) properties of medications, including antimicrobial agents; therefore, antibiotics' dosing can be complicated in patients with AKI [2]. The main focus of studies on dosing of antimicrobials in patients with AKI was in critically ill patients with sepsis and AKI, who were receiving renal replacement therapy (RRT); however, specific PK/PD data about antibiotics in patients with AKI, not requiring RRT, are rare [2, 3]. Also, there is no specific guideline in antimicrobial dosing in patients with AKI, and recommended dose adjustment for antibiotics in patients with impaired renal function is derived from studies in chronic kidney injury (CKD). This problem is too important in sepsis-related AKI, as the main cornerstone of 
treatment is the appropriate selection and dosing of antimicrobials, and it is proven that inappropriate dosing of antibiotics could significantly increase the sepsis-related mortality and treatment complications [3].

In 2010, the organization of Kidney Disease: Improving Global Outcomes (KDIGO) held a conference to investigate the drug dosage approach in patients with renal impairment. The consensus about dosing adjustment of hydrophilic antibiotics, including $\beta$-lactam in AKI, is the administration of high loading doses and suggested that the maintenance dose of antibiotics should be initiated at normal or near-normal dosage regimens [4]. Despite this recommendation, to the best of our knowledge, no study has been evaluated PK/PD properties of $\beta$-lactam antibiotics with recommended doses in patients with AKI, not requiring RRT.

Meropenem is a broad-spectrum $\beta$-lactam antibiotic, which is frequently used for empiric treatment of nosocomial infections in critically ill patients [5]. The PD activity of meropenem is time-dependent. Minimum plasma concentrations $\left(C_{\mathrm{min}}\right)$ higher than the minimum inhibitory concentration (MIC) for an adequate percentage of time in a dosing interval (\% $\%$ t > MIC), must be maintained for bactericidal efficacy [6, 7], and prolonged infusions rather than increasing the dose, could optimize the effect of this antibiotic [8-10]. Meropenem undergoes extensive renal elimination, with a clearance (CL) of approximately $10-12 \mathrm{~L} / \mathrm{h}$ in most studies [6, 8], and in subjects with normal renal function, the elimination half-life (T1/2) of meropenem is approximately $1 \mathrm{~h}$. The plasma protein binding of meropenem is approximately $2 \%$ and the volume of distribution (Vd) at steady-state is around 15-20 $\mathrm{L}[11]$. A 3-h infusion of $1 \mathrm{~g}$ of meropenem in healthy persons produce a mean peak plasma concentration (Cmax) of $25 \mu \mathrm{g} /$ $\mathrm{mL}[11]$. Considering these PK/PD characteristics in the dosing of antimicrobials could maximize efficacy, minimize the antimicrobial resistance, and concentration-related adverse effects [3].

The primary objective of the current study was the evaluation of the time that plasma concentrations remain above four times the MIC ( $\mathrm{ft}>4 \mathrm{MIC}$ ) as an index for meropenem efficacy in critically ill patients with AKI, not receiving RRT, with two dosing regimens, adjusted based on calculated creatinine clearance $(\mathrm{CrCl})$ by the Cockcroft-Gault $(\mathrm{C}-\mathrm{G})$ formula, compared to the standard dosing regimen. As a secondary goal, we evaluated the PK parameters of meropenem is this setting.

\section{Materials and methods}

\section{Settings}

The present prospective, randomized clinical trial (RCT), was conducted in a 30-bed medical-surgical intensive care unit (ICU) of Imam Hossein Medical Center, affiliated with Shahid Beheshti University of Medical Sciences (SBMU) in Tehran, Iran, from July 2018 to August 2019. This study has been approved by the Institutional Review Boards of the Ethics Committee of SBMU (IR.SBMU.PHNM.1397.38). Also, the study protocol was registered, reviewed, and approved by the Iranian Registry of Clinical Trials (IRCT), with the registry number of IRCT20160412027346N5.

\section{Study population}

All patients older than 18 years, who developed AKI based on Acute Kidney Network (AKIN) and/or Risk, Injury, Failure, Loss, End-stage renal disease (RIFLE) criteria [12], and treated with standard dose of meropenem( $(1$ gram $(\mathrm{g})$ every $8 \mathrm{~h}$ ( $3 \mathrm{~g}$ daily)) based on the physician in charge decision, were included in the study. Patients with one of the following criteria were excluded: CKD, RRT, pregnancy, lactation, and receiving an adjusted dose of meropenem before recruitment.

\section{Interventions}

All patients admitted to the ICU were evaluated according to the AKIN and RIFLE criteria on the first day of admission. All patients who were included in the study received standard dose of meropenem ( $1 \mathrm{~g}$ every $8 \mathrm{~h}$ ( $3 \mathrm{~g}$ daily)), based on the diagnosis (empiric or culture-based) for $48 \mathrm{~h}$. Each dose of meropenem was infused over $4 \mathrm{~h}$. After $48 \mathrm{~h}$ (classified as the early phase), blood samples were obtained at the following times: $1 \mathrm{~h}$ after the end of infusion (peak concentration (Cpeak)), and $30 \mathrm{~min}$ before the start of the next dose (trough concentration (Ctrough) ) [13]. Then, patients were enrolled in two treatment groups: standard or adjusted. The standard group received meropenem without dose adjustment, but in another group adjusted doses were administered to the patients based on calculated $\mathrm{CrCl}$ by the $\mathrm{C}-\mathrm{G}$ equation as follows: $\mathrm{CrCl} \geq 50 \mathrm{ml} / \mathrm{min}$ : no dosage adjustment, $\mathrm{CrCl}: 25-50 \mathrm{ml} /$ min: recommended dose every $12 \mathrm{~h}, \mathrm{CrCl}: 10-25 \mathrm{ml} / \mathrm{min}$ : one-half recommended dose every $12 \mathrm{~h}, \mathrm{CrCl}<10 \mathrm{ml} / \mathrm{min}$ : one-half recommended dose every $24 \mathrm{~h}$ [14]. Sampling was repeated on the fifth day after the administration of meropenem (classified as the late phase) for the measurement of Cpeak and Ctrough. Blood samples were immediately centrifuged for $15 \mathrm{~min}$ at $4000 \mathrm{~g}$, and serum was stored at $-80^{\circ} \mathrm{C}$ for later analysis.

For all patients, the following variables were recorded: age, sex, ideal body weight (IBW), baseline serum creatinine ( $\mathrm{Scr}$ ), stage of AKIN and RIFLE criteria in the recruitment day, Scr and estimated $\mathrm{CrCl}$ by the $\mathrm{C}-\mathrm{G}$ equation in the recruitment day, and duration of antibiotic therapy. 


\section{Meropenem assay}

Serum concentrations were determined by highperformance liquid chromatography (HPLC) with an ultraviolet (UV) detector. Then, $950 \mu$ l of plasma was precipitated with $1000-\mu \mathrm{l}$ acetonitrile, containing $50 \mu \mathrm{l}$ of acetaminophen as the internal standard. After vortexing and centrifugation at $4000 \mathrm{~g}$ for $10 \mathrm{~min}, 20 \mu \mathrm{l}$ was injected into the HPLCUV system. The mobile phase consisted of water-ammonium acetate-acetonitrile $(60 \%, 31 \%, 9 \%)$ at $\mathrm{pH} 4$ with an injection rate of $1 \mathrm{ml} / \mathrm{min}$. The separation was performed on an analytical C18 column $(250 \mathrm{~mm} \times 4.6 \mathrm{~mm}$ with 5 - $\mu \mathrm{m}$ spherical particles). The UV detection was at $298 \mathrm{~nm}$. The calibration curve was constructed by linear regression of analyteinternal standard area ratios; the method was validated over the concentration range of $2.5-80 \mu \mathrm{g} / \mathrm{mL}$. The limit of quantitation (LOQ) was $1.25 \mu \mathrm{g} / \mathrm{mL}$ [15].

\section{Definition}

$\mathrm{CrCl}$ calculated according to the Cockcroft-Gault formula as:

$$
\begin{aligned}
\mathrm{C}-\mathrm{G}(\mathrm{ml} / \mathrm{min})= & \frac{140-\operatorname{age}(\mathrm{y}) \times \operatorname{weight}(\mathrm{Kg})}{\text { Serum creatinine }\left(\frac{\mathrm{mg}}{\mathrm{dL}}\right) \times 72} \\
& \times(0.85 \text { if female })
\end{aligned}
$$

We used IBW for calculating $\mathrm{CrCl}$ with the $\mathrm{C}-\mathrm{G}$ formula. Thus, participants' heights were estimated (for those without this record), based on the length of the ulna (Malnutrition Universal Screening Tool (MUST) equation) [16].

The PK parameters for plasma meropenem concentration were calculated according to Eqs. 1 to 5:

$$
\begin{aligned}
& \mathrm{CL}(\mathrm{L} / \mathrm{h})=\frac{[\text { Dose } / \mathrm{T}]}{\text { Css ave }} \\
& \mathrm{K}\left(\begin{array}{c}
-1 \\
\text { min }
\end{array}\right)=\frac{\ln [\text { Cpeak } / \text { Ctrough }]}{\mathrm{t}} \\
& \mathrm{Vd}(\mathrm{L})=\frac{\mathrm{CL}}{\mathrm{K}} \\
& \mathrm{T} 1 / 2(\mathrm{~h})=\frac{0.693}{\mathrm{~K}} \\
& \text { Css ave }(\mu \mathrm{g} / \mathrm{mL})=\frac{[\text { Cpeak }+ \text { Ctrough }]}{2}
\end{aligned}
$$

"CL" is the clearance of meropenem, " $\mathrm{K}$ " is the elimination rate constant, "Vd" is the volume of distribution, and " $\mathrm{T} 1 / 2$ " is terminal half-life. Cpeak and Ctrough are the concentrations measured at the $1 \mathrm{~h}$ after the end of infusion, and $30 \mathrm{~min}$ before the start of the next infusion, and " $\mathrm{t}$ " is the time interval between the measurements. Css ave is the average steady-state concentrations of meropenem and " $\Gamma$ " is the dosing interval [13].

\section{PD end-point}

In this study, the efficacy of meropenem therapy was assessed by calculating the time above four times the target MIC ( $\mathrm{ft}>$ $4 \mathrm{MIC}$ ). The $\mathrm{ft}>4 \mathrm{MIC}$ was calculated using series of pharmacokinetic formulas in appendix 1 . The optimal goal of $\mathrm{ft}$ was considered $\geq 80 \%$ for meropenem in Gram-negative bacterial infections [17]. In our study, measured concentrations were compared to the European Committee on Antimicrobial Susceptibility Testing (EUCAST) of susceptible breakpoints for the Gram-negative organism, $2 \mu \mathrm{g} / \mathrm{mL}$ for meropenem.

\section{Sample size}

The sample size of the study was calculated with Minitab software using the sample size for 2 sample $t$ test function considering type I error of 0.05 , power of $0.8, \mathrm{ft}>4 \mathrm{MIC}$ in adjusted group $58.83 \% \pm 21.2 \%$ [7] and in standard group $88 \%$. The sample size was calculated as 10 patients in each group.

\section{Statistical analysis}

All statistical analyses were performed, using SPSS for Windows (Version 21.0; SPSS Inc., Chicago, IL, USA). Quantitative data were tested for normality of distributions by the Shapiro-Wilk test, and then compared by unpaired student's $t$ test and Mann-Whitney $U$ test for normal and nonnormal data, respectively. Qualitative data were analyzed by the chi squared test, and a $P$ value of $<0.05$ was considered significant.

Baseline characteristics and $\mathrm{PK} / \mathrm{PD}$ data are presented as mean \pm standard deviation (SD) or median (interquartile range (IQR)) for normal and nonnormal distribution, respectively, and range (Min-Max) based on the parameters. A Spearman correlation coefficient was computed to assess the relationship between variables.

\section{Results}

\section{Baseline characteristics}

During the 13-month of the study period, 1334 patients were admitted to the ICU, 171 patients suffered from AKI and 43 patients recruited, and finally, 16 patients ( 7 and 9 in standard and adjusted arms of the study) completed the study. Details are shown in Fig. 1. There was no statistically significant difference between the two groups in all measured baseline characteristics and parameters related to renal function. The results are shown in Tables 1 and 2. 
At total, we obtained 25 paired samples (Cpeak and Ctrough); 10 and 15 pairs in the early and late phases of the study, respectively.

\section{Pharmacokinetic/pharmacodynamic data}

The mean $\pm \mathrm{SD}$ or median (IQR), and the range of meropenem's PK parameters for two groups in the early and late phases of meropenem treatment are shown in Table 3. In a comparison of PK parameters between the two groups, there were no statistically significant differences in all measured PK parameters.

The mean $\pm \mathrm{SD}$ of the dose and $\mathrm{ft}>4 \mathrm{MIC}$ of meropenem in the late phase was $3 \mathrm{~g} /$ day vs $2.17 \pm 0.94 \mathrm{~g} /$ day $(t(8)=2.67, p$ $=0.028)$ and $54.81 \pm 27.24 \%$ vs $54.64 \pm 27.19 \%(t(13)=$ $0.011, p=0.991)$ in standard and adjusted group.

In all 25 paired samples, $\mathrm{CrCl}$ based on the $\mathrm{C}-\mathrm{G}$ was (median $42.59 \mathrm{ml} / \mathrm{min}$; IQR $28.12-59.44 \mathrm{ml} / \mathrm{min}$ ), $\mathrm{ft}>4 \mathrm{MIC}$ was (median 61.06\%; IQR 41.49-76.11\%), also PK parameters were as follows: Cpeak (median $19.32 \mu \mathrm{g} / \mathrm{mL}$; IQR $14.91-$ $31.39 \mu \mathrm{g} / \mathrm{mL}$ ), Ctrough (median $11.02 \mu \mathrm{g} / \mathrm{mL}$; IQR 7.13$17.23 \mu \mathrm{g} / \mathrm{mL}$ ), CL of meropenem (median $6.52 \mathrm{~L} / \mathrm{h}$; IQR $4.33-10.16 \mathrm{~L} / \mathrm{h}), \mathrm{K}$ (median $0.0025 \mathrm{~min}^{-1}$; IQR $0.0013-$ $\left.0.0043 \mathrm{~min}^{-1}\right)$, Vd (median 46.04 L; IQR 23.06-103.18 L), T 1/2 (median $4.51 \mathrm{~h}$; IQR 2.67-8.88 h).

\section{Meropenem plasma concentrations}

All measured concentrations (Cpeak and Ctrough) based on the dose and $\mathrm{CrCl}$ calculated by the $\mathrm{C}-\mathrm{G}$ formula are shown in Fig. 2. The large variety of concentrations was seen in patients with different $\mathrm{CrCl}$ in a similar dose of meropenem. Table 4 shows the meropenem concentrations in each dose at the early and late phases of administration, regardless of the groups.

Also, Fig. 3 shows the mean meropenem concentrations for two groups in the two phases of study.

In the early phase, all patients were treated with 3 -g meropenem daily, and there were not statistically significant differences between the mean concentrations in the adjusted and standard groups (Cpeak: $33.02 \pm 19.75 \mu \mathrm{g} / \mathrm{mL}$ vs $21.11 \pm$ $12.31 \mu \mathrm{g} / \mathrm{mL}(p=0.319)$ and Ctrough: $17.27 \pm 13.78 \mu \mathrm{g} / \mathrm{mL}$ vs $12.36 \pm 5.50 \mu \mathrm{g} / \mathrm{mL}(p=0.670)$ in adjusted and standard arms of the study respectively). Also the mean $\mathrm{CrCl}$ was not statistically different between two arms of the study (35.09 \pm $17.66 \mathrm{ml} / \mathrm{min}$ vs $53.02 \pm 48.28 \mathrm{ml} / \mathrm{min}(p=1)$ ).

In the late phase, although the mean dose of meropenem in the adjusted group was lower than the standard group (2.17 \pm $0.94 \mathrm{~g}$ vs $3 \mathrm{~g}(p=0.028))$, the mean concentrations were not statistically significant differences (Cpeak: $20.68 \pm 7.28 \mu \mathrm{g}$ / $\mathrm{mL}$ vs $19.40 \pm 11.31 \mu \mathrm{g} / \mathrm{mL}(p=0.793)$ and Ctrough: $12.29 \pm$ $6.34 \mu \mathrm{g} / \mathrm{mL}$ vs $11.10 \pm 7.63 \mu \mathrm{g} / \mathrm{mL}(p=0.746)$ in adjusted and standard arms of the study, respectively). The mean $\mathrm{CrCl}$ was not statistically different between two groups (52.22 \pm $28.74 \mathrm{ml} / \mathrm{min}$ vs $54.39 \pm 36.09 \mathrm{ml} / \mathrm{min}(p=0.899))$.

\section{Meropenem concentrations and renal function}

We evaluated the correlation of Ctrough with measured and calculated predictors of renal function, including Scr and $\mathrm{CrCl}$ calculated with $\mathrm{C}-\mathrm{G}$ in patients who treated with $3 \mathrm{~g}$ daily of meropenem in the current study. We could not find significant correlation between Ctrough with $\operatorname{Scr}(r=0.114, n=20, p=$ 0.632). However, the correlation between Ctrough and

Table 1 Baseline characteristics of participants in two arms of the study

\begin{tabular}{|c|c|c|c|c|c|c|}
\hline & & \multicolumn{4}{|c|}{ Groups } & \multirow[t]{3}{*}{ Sig ${ }^{a, b, c}$} \\
\hline & & \multicolumn{2}{|c|}{ Standard dose } & \multicolumn{2}{|c|}{ Adjusted dose } & \\
\hline & & Count & Mean $\pm \mathrm{SD}^{\mathrm{d}}$ & Count & Mean $\pm \mathrm{SD}^{\mathrm{d}}$ & \\
\hline \multirow[t]{2}{*}{ Sex } & Male & 4 & & 5 & & \multirow[t]{2}{*}{0.949} \\
\hline & Female & 3 & & 4 & & \\
\hline Age (year) & & 7 & $62.43 \pm 14.34$ & 9 & $54.78 \pm 24.35$ & 0.475 \\
\hline $\mathrm{IBW}^{\mathrm{e}}(\mathrm{Kg})$ & & & $67.43 \pm 12.24$ & & $64.36 \pm 9.65$ & 0.582 \\
\hline \multirow[t]{6}{*}{ Indication of meropenem } & $V_{A P}^{f}$ & 5 & & 4 & & \multirow[t]{6}{*}{0.423} \\
\hline & Peritonitis & 1 & & 1 & & \\
\hline & $\mathrm{COPD}^{\mathrm{g}}$ exacerbation & 0 & & 2 & & \\
\hline & $\mathrm{PJI}^{\mathrm{h}}$ & 1 & & 0 & & \\
\hline & Pressure ulcer infection & 0 & & 1 & & \\
\hline & $\mathrm{HAP}^{\mathrm{i}}$ & 0 & & 1 & & \\
\hline
\end{tabular}

a Unpaired student's $t$ test; ${ }^{\mathrm{b}}$ Mann-Whitney $U$ test; ${ }^{\mathrm{c}}$ chi square test $;{ }^{\mathrm{d}}$ standard deviation; ${ }^{\mathrm{e}}$ ideal body weight; ${ }^{\mathrm{f}}$ ventilator-associated pneumonia;

${ }^{\mathrm{g}}$ chronic obstructive pulmonary disease; ${ }^{\mathrm{h}}$ prosthetic joint infection; ${ }^{\mathrm{i}}$ hospital-acquired pneumonia 
Table 2 Parameters related to renal function and dose of meropenem

\begin{tabular}{|c|c|c|c|c|c|c|}
\hline & & \multicolumn{4}{|c|}{ Groups } & \multirow[t]{3}{*}{ Sig ${ }^{a, b, c}$} \\
\hline & & \multicolumn{2}{|c|}{ Standard dose } & \multicolumn{2}{|c|}{ Adjusted dose } & \\
\hline & & Count & Mean $\pm \mathrm{SD}^{\mathrm{d}}$ & Count & Mean $\pm \mathrm{SD}^{\mathrm{d}}$ & \\
\hline \multicolumn{2}{|l|}{$\mathrm{Scr}^{\mathrm{e}}$ at baseline } & & $0.89 \pm 0.22$ & & $0.87 \pm 0.19$ & 0.856 \\
\hline \multirow[t]{3}{*}{ Stage of AKIN ${ }^{\mathrm{f}}$} & Stage 1 & 5 & & 4 & & 0.430 \\
\hline & Stage 2 & 1 & & 1 & & \\
\hline & Stage 3 & 1 & & 4 & & \\
\hline \multirow[t]{5}{*}{ Stage of RIFLE ${ }^{\mathrm{g}}$} & Risk & 4 & & 4 & & 0.384 \\
\hline & Injury & 2 & & 1 & & \\
\hline & Failure & 1 & & 4 & & \\
\hline & Loss & 0 & & 0 & & \\
\hline & End stage & 0 & & 0 & & \\
\hline \multicolumn{2}{|l|}{ Duration of $\mathrm{AKI}^{\mathrm{h}}$ (day) } & & $15.57 \pm 8.96$ & & $16.78 \pm 10.40$ & 0.811 \\
\hline \multirow[t]{2}{*}{ Recruitment day } & $\mathrm{Scr}^{\mathrm{e}}$ & & $1.96 \pm 0.76$ & & $2.14 \pm 0.91$ & 0.686 \\
\hline & $C-G^{i}$ & & $38.17 \pm 10.24$ & & $36.40 \pm 20.53$ & 0.840 \\
\hline \multirow[t]{2}{*}{ Early phase $^{j}$} & $\mathrm{Scr}^{\mathrm{e}}$ & & $1.45 \pm 0.62$ & & 2. $48 \pm 1.35$ & 0.194 \\
\hline & C-G $\mathrm{G}^{\mathrm{i}}$ & & $53.02 \pm 48.28$ & & $35.09 \pm 17.66$ & 1 \\
\hline \multirow[t]{2}{*}{ Late phase ${ }^{\mathrm{k}}$} & $\mathrm{Scr}^{\mathrm{e}}$ & & $1.63 \pm 0.7$ & & $1.86 \pm 1.13$ & 0.677 \\
\hline & $C-G^{i}$ & & $54.39 \pm 36.09$ & & $52.22 \pm 28.74$ & 0.899 \\
\hline \multirow[t]{2}{*}{ Dose of meropenem(g/day) } & Early phase $\mathrm{e}^{\mathrm{j}}$ & & 3 & & 3 & \\
\hline & Late phase $\mathrm{k}^{\mathrm{k}}$ & & 3 & & $2.17 \pm 0.94$ & 0.028 \\
\hline
\end{tabular}

${ }^{\mathrm{a}}$ Unpaired student's $t$ test; ${ }^{\mathrm{b}}$ Mann-Whitney $U$ test; ${ }^{\mathrm{c}}$ chi square test $;{ }^{\mathrm{d}}$ standard deviation; ${ }^{\mathrm{e}}$ serum creatinin $(\mathrm{mg} / \mathrm{dL}) ;{ }^{\mathrm{f}}$ Acute Kidney Injury Network diagnostic criteria; ${ }^{\mathrm{g}}$ Risk, Injury, Failure; Loss, End-Stage Renal Disease diagnostic criteria; ${ }^{\mathrm{h}}$ acute kidney injury; ${ }^{\mathrm{i}}$ Cockcroft-Gault (ml/min); ${ }^{\mathrm{j}} 2 \mathrm{nd}$ day of study (after $48 \mathrm{~h}) ;{ }^{\mathrm{k}} 5$ th day of the study

calculated $\mathrm{CrCl}$, using the $\mathrm{C}-\mathrm{G}$ formula was statistically significant $(r=-0.484, n=20, p=0.031)$.

Also, we assessed the relationship between the clearance of meropenem with $\mathrm{C}-\mathrm{G}$ in this subgroup. There was a significant correlation between two variables $(r=0.453, n=20, p=$ 0.047).

\section{PD end-point}

In the early phase, 3 out of $10(30 \%)$ patients attained the desired PD target, and one patient achieved $100 \% \mathrm{ft}>4 \mathrm{MIC}$. In the late phase, the desired PD target was attained in 2 out of $10(20 \%)$ and 1 out of $5(20 \%)$ of patients who received standard and adjusted doses of meropenem, respectively $\left(x^{2}(1, N=15)=0.000, p=1\right)$. One patient that received a standard dose ( $3 \mathrm{~g}$ daily) attained $100 \% \mathrm{ft}>4 \mathrm{MIC}$. We reported the PD target in each dose at two phases of the study, regardless of the groups, in Table 4.

\section{Discussion}

The main results of the present study were (i) increase of $\mathrm{Vd}$ and $\mathrm{T} 1 / 2$ and decrease of clearance of meropenem, as shown in critically ill patients with AKI, who did not receive RRT (ii) plasma concentrations varied between patients with different $\mathrm{CrCl}$ in a similar dose of meropenem (iii) fail to reach the PD parameter of $\geq 80 \% \mathrm{ft}>4 \mathrm{MIC}$ in 75 and $80 \%$ of patients who received standard and adjusted dose (iv) significant correlation between calculated $\mathrm{CrCl}$ by the $\mathrm{C}-\mathrm{G}$ equation with plasma concentration and clearance of meropenem.

PK/PD properties of antibiotics in critically ill patients, especially in AKI conditions, were different in comparison with healthy volunteers and CKD patients; therefore, approaches to antimicrobial dose adjustment in patients with AKI are controversial [3]. In critically ill patients with sepsis, several factors such as vasoplegia and capillary leak, administration of large volume of fluid and blood can lead to increases in $\mathrm{Vd}$ and proportionally prolonged the $\mathrm{T} 1 / 2$ [18]. The $\mathrm{Vd}$ of meropenem in healthy volunteers is $15-20 \mathrm{~L}$ [11], and in the CKD patients, moderate to severe renal impairment without receiving RRT $(\mathrm{CrCl}: 6.1-17.1 \mathrm{ml} / \mathrm{min})$, is 19.65 $26.71 \mathrm{~L}$ [19]. Also, several studies in the critically ill patients have shown that Vd increased (21.7-34.4 L) [18, 20, 21], and the results of our study corroborate the finding of these studies, indicating that $\mathrm{Vd}$ increased in critically ill patients with AKI (median 46.04 L; IQR 23.06-103.18 L). The T1/2 reported in CKD patients was 4-5-fold higher than those 


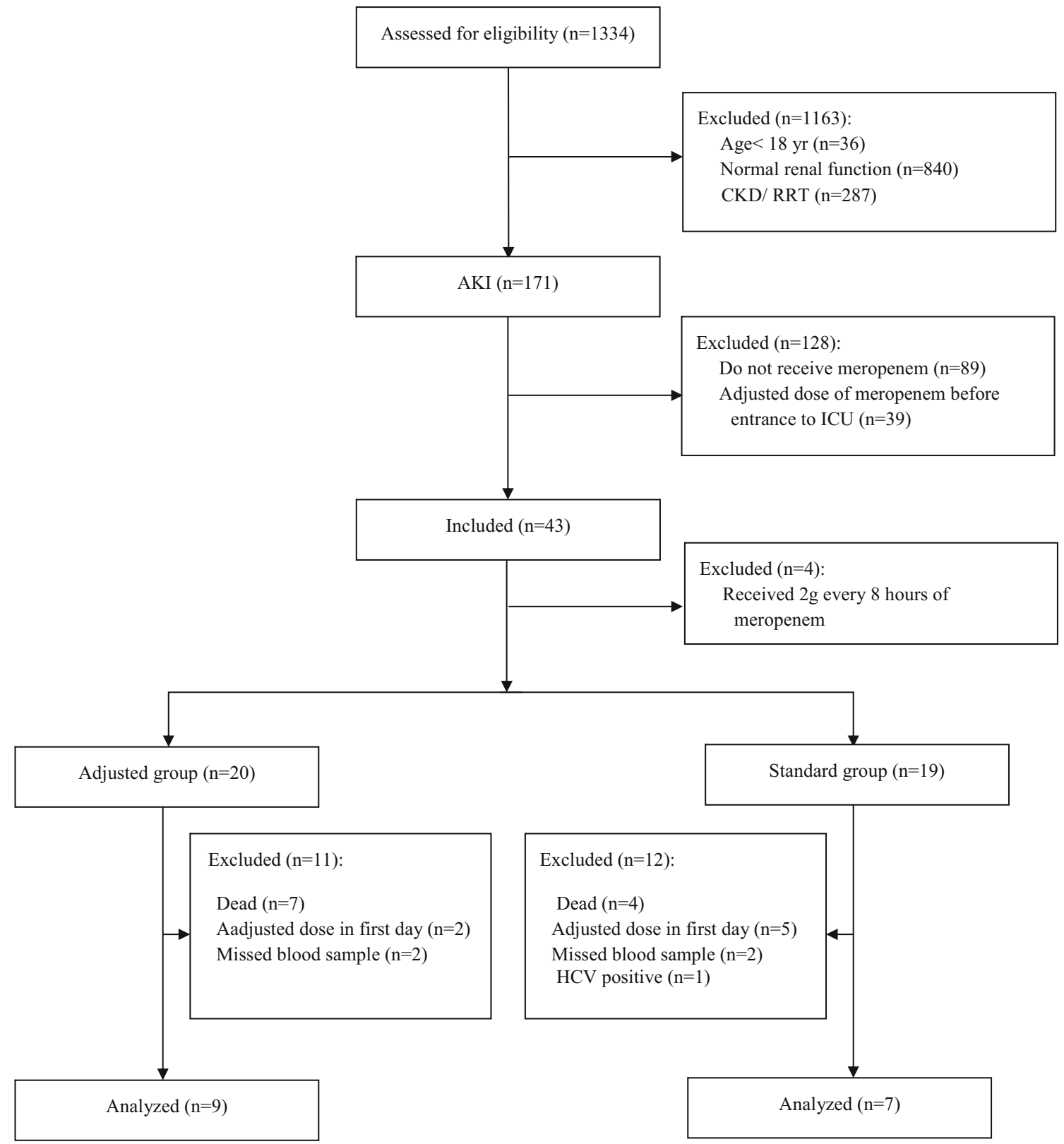

Fig. 1 Consort chart of the study. CKD: chronic kidney disease; AKI: acute kidney injury; RRT: renal replacement therapy; HCV: hepatitis C virus; ICU: intensive care unit

obtained in healthy volunteers $(4.59-5.73 \mathrm{~h}$ vs $1 \mathrm{~h})[19]$ and $\mathrm{T} 1 / 2$ is $2.22-2.52 \mathrm{~h}$ in critically ill patients $[9,20,21]$. T1/2 reported in our study was prolonged, compared to the healthy volunteers (median $4.51 \mathrm{~h}$; IQR 2.67-8.88 h).

Several studies in septic ICU patients reported high clearance of antibiotics due to hyperdynamic conditions and as a consequence of augmented renal perfusion, following aggressive fluid load and use of inotropic therapy $[3,18,22]$. Nowadays, this phenomenon named augmented renal clearance (ARC), and it is a reason for the increase of clearance and low concentrations of antimicrobial agents in critically ill patients with normal Scr [22].
Jaruratanasirikul et al. [21] evaluated the PK parameters of meropenem in the early phase of severe sepsis and septic shock in ICU patients without a history of CKD, and showed that clearance of meropenem was lower than the values obtained from healthy volunteers $(7.82 \mathrm{~L} / \mathrm{h}$ vs. $12.97 \pm 0.18 \mathrm{~L} / \mathrm{h})$ $[8,21]$. They concluded that renal clearance may be decreased with organ dysfunctions, which can occur with severe sepsis and septic shock [21]. Consistent with the noted study, the clearance of meropenem was lower in comparison with healthy volunteers in our study (median $6.52 \mathrm{~L} / \mathrm{h}$; IQR 4.33 $10.16 \mathrm{~L} / \mathrm{h}$ ). The clearance of meropenem in the moderate to severe CKD patients was $2.52-4.62 \mathrm{~L} / \mathrm{h} \mathrm{[19]}$. 
Table 3 Pharmacokinetic data of meropenem

\begin{tabular}{|c|c|c|c|c|c|c|}
\hline & & \multicolumn{4}{|l|}{ Groups } & \multirow[t]{3}{*}{ Sig ${ }^{a, b}$} \\
\hline & & \multicolumn{2}{|l|}{ Standard dose } & \multicolumn{2}{|l|}{ Adjusted dose } & \\
\hline & & Min-Max & Mean $\pm \mathrm{SD} /$ median $(\mathrm{IQR})^{\mathrm{c}}$ & Min-Max & Mean $\pm \mathrm{SD} /$ median $(\mathrm{IQR})^{\mathrm{c}}$ & \\
\hline \multirow[t]{2}{*}{$\mathrm{C}^{\mathrm{d}}$ peak } & Early phase $^{\mathrm{i}}$ & $7.89-36.98$ & $21.11 \pm 12.31$ & $10.30-57.07$ & $33.02 \pm 19.75$ & 0.319 \\
\hline & Late phase $\mathrm{e}^{\mathrm{j}}$ & $7.67-34.48$ & $19.40 \pm 11.31$ & $9.65-32.88$ & $20.68 \pm 7.29$ & 0.793 \\
\hline \multirow[t]{2}{*}{$\mathrm{C}^{\mathrm{d}}$ trough } & Early phase & $4.43-16.88$ & $14.06(8.77-15.94)$ & $7.34-44.02$ & $12.84(8.54-18)$ & 0.670 \\
\hline & Late phase & $3.87-23.32$ & $11.10 \pm 7.63$ & $4.81-22.11$ & $12.29 \pm 6.34$ & 0.746 \\
\hline \multirow[t]{2}{*}{$\mathrm{CL}^{\mathrm{e}}$} & Early phase & $4.64-20.26$ & $9.98 \pm 7.04$ & $2.47-14.16$ & $6.94 \pm 4.47$ & 0.422 \\
\hline & Late phase & $4.60-18.99$ & $11.04 \pm 6.09$ & $2.02-9.77$ & $5.78 \pm 2.76$ & 0.092 \\
\hline \multirow[t]{2}{*}{$K_{e}{ }^{f}$} & Early phase & $0.0013-0.0048$ & $0.0037 \pm 0.0016$ & $0.0015-0.0083$ & $0.0038 \pm 0.0026$ & 0.951 \\
\hline & Late phase & $0.0007-0.0042$ & $0.0029 \pm 0.0015$ & $0.0005-0.0056$ & $0.0021 \pm 0.0019$ & 0.429 \\
\hline \multirow[t]{2}{*}{$V_{d}{ }^{g}$} & Early phase & $18.25-108.51$ & $55.42 \pm 42.29$ & $7.66-104.71$ & $43.36 \pm 35.85$ & 0.640 \\
\hline & Late phase & $19.27-408.72$ & $46.30(37.04-123.82)$ & $18.62-238.18$ & 74.66 (26.94-101.65) & 0.906 \\
\hline \multirow[t]{2}{*}{$\mathrm{T}_{1 / 2}{ }^{\mathrm{h}}$} & Early phase & $2.40-8.84$ & $4.14 \pm 3.13$ & $1.38-7.78$ & $4.37 \pm 2.55$ & 0.902 \\
\hline & Late phase & $2.76-16.53$ & $6.04 \pm 5.37$ & $2.05-23.65$ & $11.10 \pm 8.31$ & 0.212 \\
\hline
\end{tabular}

${ }^{\mathrm{a}}$ Unpaired student's $t$ test; ${ }^{\mathrm{b}}$ Mann-Whitney $U$ test; ${ }^{\mathrm{c}}$ Values reported as mean \pm standard deviation or median (interquartile range: $25 \%, 75 \%$ ) for normal or non-normal distribution, respectively; ${ }^{\mathrm{d}}$ Concentration $(\mu \mathrm{g} / \mathrm{mL}) ;{ }^{\mathrm{e}}$ Total clearance $(\mathrm{L} / \mathrm{hr}) ;{ }^{\mathrm{f}}$ Elimination rate constant $\left(\mathrm{min}^{-1}\right) ;{ }^{\mathrm{g}}$ Volume of distribution (L); ${ }^{\mathrm{h}}$ Elimination half-life (h); ${ }^{\mathrm{i}}$ 2nd day of study (after $\left.48 \mathrm{~h}\right) ;{ }^{\mathrm{j}}$ 5th day of the study

The observed significant and positive correlation between the clearance of meropenem and C-G, and significant and the negative correlation of meropenem serum concentration with $\mathrm{C}-\mathrm{G}$, can prove the relationship between renal function and clearance of drugs $[19,20]$. This is also consistent with evidence from an observational study conducted by Petersson et al. [22], showing that measured $\mathrm{CrCl}$ is better than $\mathrm{Scr}$ in predicting serum concentration of meropenem.

The study population is the most significant difference in our study compared with other studies about meropenem PK/ PD parameters in critically ill patients. In other studies, AKI patients specifically are not the target population or are

Table 4 Meropenem concentrations ( peak \& trough concentrations) in each dose at early and late phases of meropenem administration

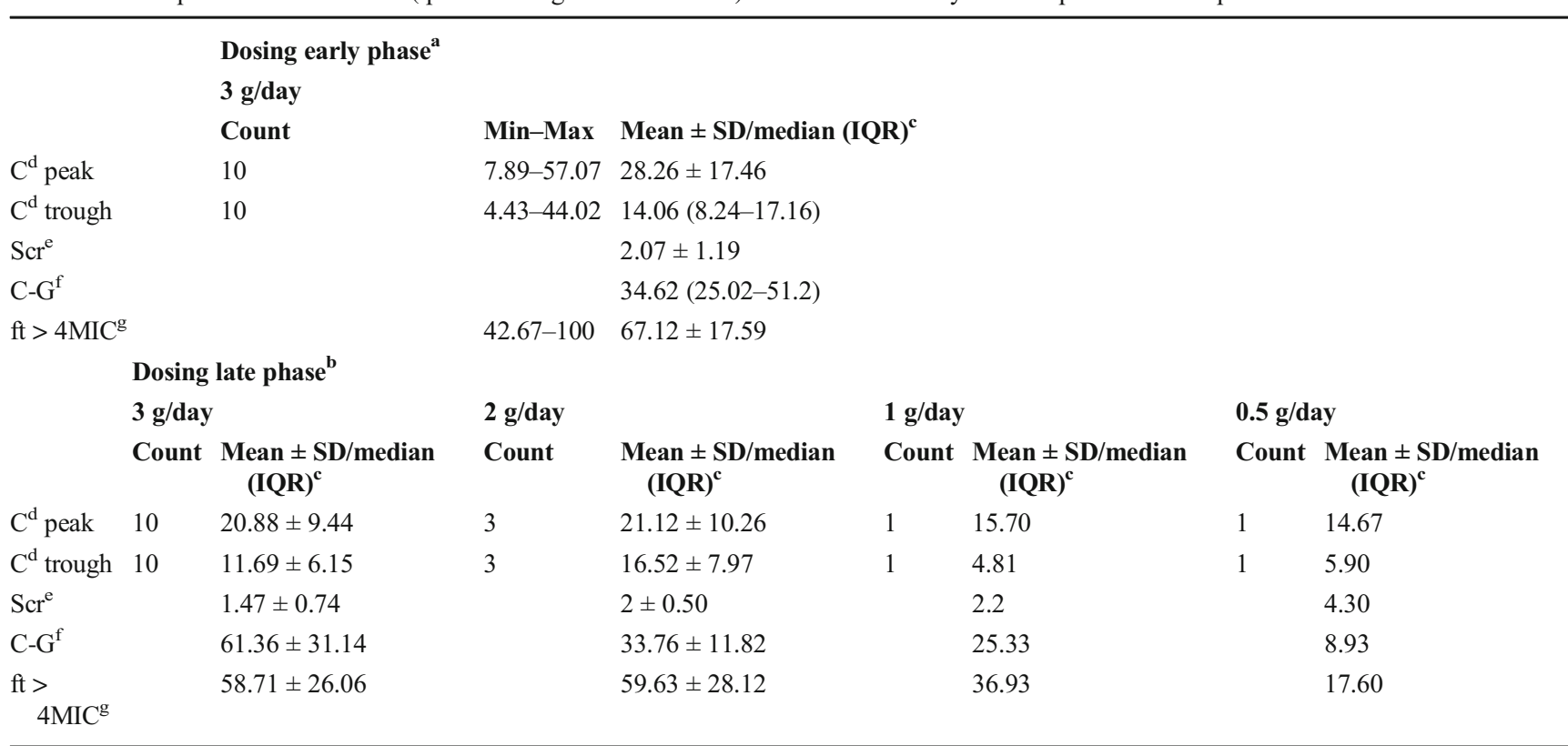

${ }^{\mathrm{a}} 2^{\text {nd }}$ day of study (after $\left.48 \mathrm{~h}\right) ;{ }^{\mathrm{b}} 5^{\text {th }}$ day of the study; ${ }^{\mathrm{c}}$ Values reported as mean \pm standard deviation or median (interquartile range: $25 \%, 75 \%$ ) for normal or nonnormal distribution, respectively; ${ }^{\mathrm{d}}$ Concentration $(\mu \mathrm{g} / \mathrm{mL})$; ${ }^{\mathrm{e}}$ Serum creatinin $(\mathrm{mg} / \mathrm{dL}) ;{ }^{\mathrm{f}}$ Cockcroft-Gault $(\mathrm{ml} / \mathrm{min}) ;{ }^{\mathrm{g}}$ Fraction of time $>4 \mathrm{MIC}$ (minimum inhibitor concentration, $2 \mu \mathrm{g} / \mathrm{mL})(\%)$ 


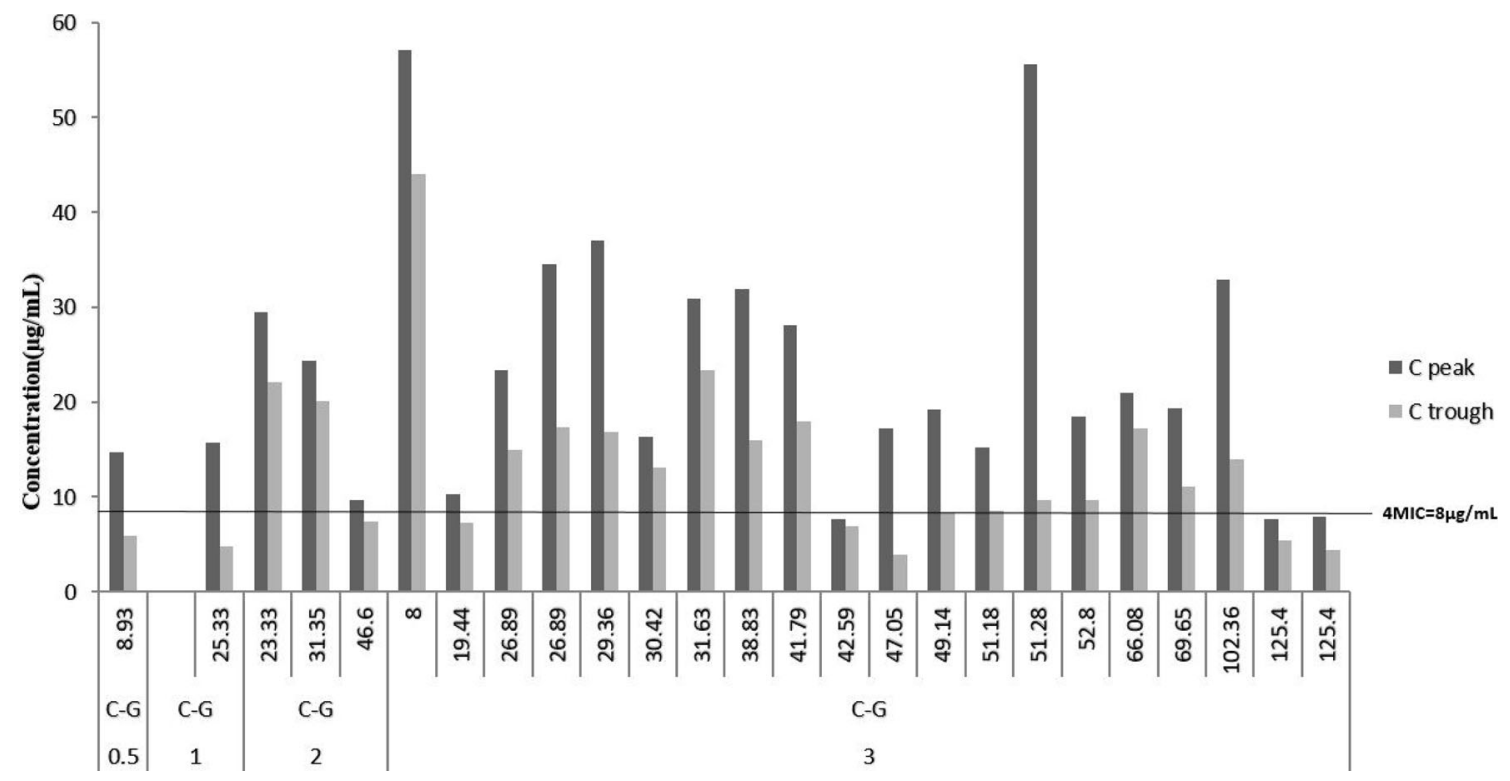

Fig. 2 All measured meropenem concentrations (peak and trough concentrations) base on the dose and $\mathrm{CrCl}$ calculated by the $\mathrm{C}-\mathrm{G}$ equation. Dose of meropenem: $0.5=0.5 \mathrm{~g} /$ day, $1=1 \mathrm{~g} /$ day, $2=2 \mathrm{~g} /$ day, $3=3$

conducted in AKI patients receiving RRT, or these studies excluded the patients with renal impairment [9, 21, 22], but what was special about our study was the critically ill AKI population, not receiving RRT.

The threshold of PD target for maximal $\beta$-lactam activity is still controversial. PD targets like concentration above four times of MIC for at least $40 \%$ dosing interval $(40 \% \mathrm{ft}>$ 4MIC) have been suggested [7, 20, 23]. According to this target, in the early phase, with standard dosing of meropenem, all patients attained target and in the late phase, $33 \%$ of patients failed to achieve the target, whereas two patients g/day. $\mathrm{C}-\mathrm{G}=$ Cockcroft-Gault $(\mathrm{C}-\mathrm{G}),(\mathrm{ml} / \mathrm{min}) ; \mathrm{MIC}=$ minimum inhibitor concentration, $2 \mu \mathrm{g} / \mathrm{mL}$

received a standard dose and three patients received an adjusted dose of meropenem. Clinical studies in critically ill patients with severe sepsis and septic shock suggested to maximize the effect of $\beta$-lactam antibiotics, it may be necessary to maintain the concentration four times the MIC for the entire dosing interval [17], therefore we considered the $\geq 80 \% \mathrm{ft}>$ MIC as optimal target attainment for meropenem in Gram-negative bacterial infections, so 75 and $80 \%$ of patients who received standard and adjusted dose fail to receive this goal.

There are no approved dosage regimen modification guidelines in AKI patients, as described for use in CKD patients.

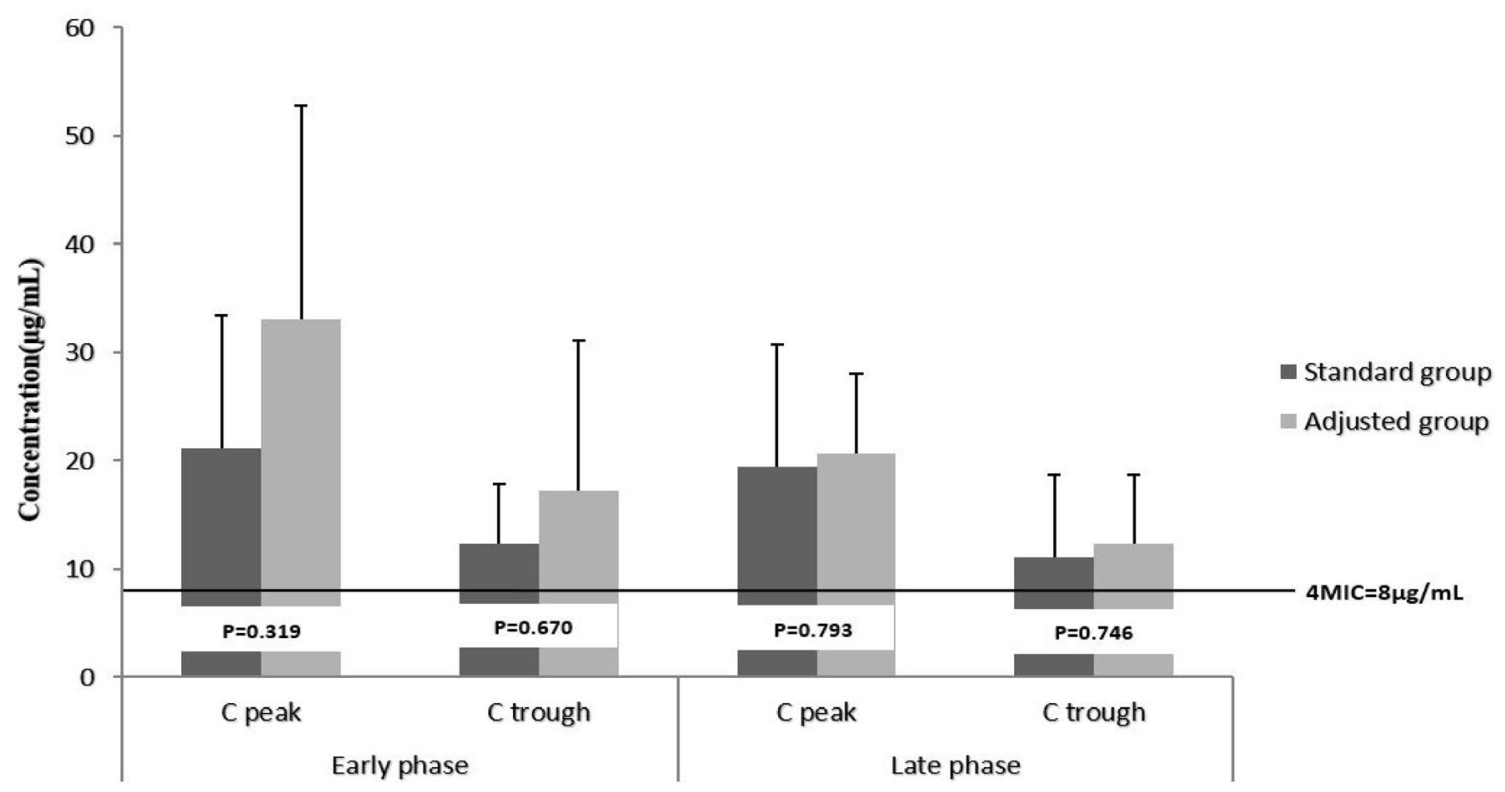

Fig. 3 Mean meropenem concentrations (peak and trough concentrations) in two groups in each phase of the study. Early phase $=2$ nd day of study (after $48 \mathrm{~h}$ ); late phase $=5$ th day of the study; $\mathrm{MIC}=$ minimum inhibitor concentration, $2 \mu \mathrm{g} / \mathrm{mL}$ 
The reviewed literature, according to the studies of the PK/PD of antibiotics in critically ill patients, proposed that as the $\mathrm{Vd}$ of the antimicrobial drugs is increased, the standard nonAKI doses should be used in the first $24-48 \mathrm{~h}$ of initiation of the therapy [3, 4]. As mentioned in the systematic review by Blot and colleagues [3] in the first 24-48 h of therapy, the concentrations of time-dependent antibiotics in critically ill patients with increased Vd will be lower than in patients with a normal $\mathrm{Vd}$ and suggested after that time, dose reduction should occur according to the renally adjusted doses [3]. Also, the KDIGO consensus recommended administration of high loading doses and the maintenance dose of antibiotics should be initiated at normal or near-normal dosage regimens [4].

Consistent with the mentioned literature, we recommend, initial doses of meropenem do not require adjustment in septic critically ill patients with AKI, not receiving RRT, for the first $48 \mathrm{~h}$. It also suggested that in the settings with a high prevalence of $\beta$-lactam-resistant strains bacteria, initiated with higher than the recommended standard doses of meropenem. After than time, maintenance dose administered higher than adjusted dose according to $\mathrm{CrCl}$, as a standard dose, or also higher than the standard dose in the sepsis and severe sepsis patients with AKI infected with a resistant strain of Gram-negative bacteria.

In the future, we suggested the evaluation of PK/PD parameters and safety of higher doses of meropenem in this population.

\section{Conclusion}

In conclusion, recommended standard doses of meropenem, $1 \mathrm{~g}$ every $8 \mathrm{~h}$ infused over $4 \mathrm{~h}$, and adjusted according to renal function failed to achieve $\geq 80 \% \mathrm{ft}>4 \mathrm{MIC}$ in critically ill patients with AKI, who not receive RRT. Higher doses, i.e., $6 \mathrm{~g}$ daily with intermittent infusion are required for this $\mathrm{PD}$ target. Also, because of PK/PD variability observed, we strongly suggest using therapeutic drug monitoring (TDM) to be sure that target drug exposure is attained.

\section{Limitation of the study}

One limitation of our study was the calculation of Css ave with Eq. 5.

Supplementary Information The online version contains supplementary material available at https://doi.org/10.1007/s00228-020-03062-0.

Acknowledgments The authors thank Nahid Shahsavari (Clinical Pharmacy laboratory, faculty of Pharmacy, Shahid Beheshti University of Medical Science (SBMU)) for her skilled technical assistance during the setup of HPLC method, also thank all the nurses of the intensive care unit (ICU) of Imam Hossein medical center for helping us during sample gathering.
Authors' contributions MS, ShZ, and MK designed the study. Literature review, drafting of the proposal, and searching were done by MS, ShZ, and RH. RH, EP, MMM, SPS, AAK, and SS helped to gather the data. FK and FN set up and interpreted the HPLC method. MS and RH analyzed and interpreted data. All authors helped to manuscript improvement and finalize the article for publication.

Data availability The data that support the findings of this study are available upon reasonable request from the corresponding author, MS. The data are not publicly available due to the containing information that could compromise the privacy of research participants.

\section{Compliance with ethical standards}

Conflict of interest The authors declare that they have no conflict of interest

Ethics approval This study has been approved by institutional review boards of the ethics committee of Shahid Beheshti University of Medical Science (SBMU) in Tehran, Iran (IR.SBMU.PHNM.1397.38).

Consent to participate Written informed consent was obtained from patients or a person's parents or legal guardians before enrollment in the study. They acknowledged that not to be identified via the paper; and that we have fully anonymized them.

Consent for publication The authors have authorized MS to act as the corresponding author for submission and during the review process.

Code availability Not applicable.

\section{References}

1. Uchino S, Kellum JA, Bellomo R, Doig GS, Morimatsu H, Morgera S, Schetz M, Tan I, Bouman C, Macedo E, Gibney N, Tolwani A, Ronco C (2005) Acute renal failure in critically ill patients: a multinational, multicenter study. Jama 294(7):813818. https://doi.org/10.1001/jama.294.7.813

2. Eyler RF, Mueller BA (2011) Antibiotic dosing in critically ill patients with acute kidney injury. Nat Rev Nephrol 7:226-235. https://doi.org/10.1038/nrneph.2011.12

3. Blot S, Lipman J, Roberts DM, Roberts JA The influence of acute kidney injury on antimicrobial dosing in critically ill patients: are dose reductions always necessary? Diagn Microbiol Infect Dis 79(1):77-84. https://doi.org/10.1016/j.diagmicrobio.2014.01.015

4. Matzke GR, Aronoff GR, Atkinson AJ Jr, Bennett WM, Decker BS, Eckardt K-U, Golper T, Grabe DW, Kasiske B, Keller F, Kielstein JT, Mehta R, Mueller BA, Pasko DA, Schaefer F, Sica DA, Inker LA, Umans JG, Murray P Drug dosing consideration in patients with acute and chronic kidney disease\&\#x2014; a clinical update from Kidney Disease: Improving Global Outcomes (KDIGO). Kidney Int 80(11):1122-1137. https://doi.org/10.1038/ ki.2011.322

5. Kees MG, Minichmayr IK, Moritz S, Beck S, Wicha SG, Kees F, Kloft C, Steinke T (2016) Population pharmacokinetics of meropenem during continuous infusion in surgical ICU patients. $\mathrm{J}$ Clin Pharmacol 56(3):307-315. https://doi.org/10.1002/jcph.600

6. Nicolau DP (2008) Pharmacokinetic and pharmacodynamic properties of meropenem. Clin Infect Dis 47(Suppl 1):S32-S40. https:// doi.org/10.1086/590064

7. Taccone FS, Laterre P-F, Dugernier T, Spapen H, Delattre I, Wittebole X, De Backer D, Layeux B, Wallemacq P, Vincent J-L, 
Jacobs F (2010) Insufficient $\beta$-lactam concentrations in the early phase of severe sepsis and septic shock. Crit Care 14(4):R126. https://doi.org/10.1186/cc9091

8. Jaruratanasirikul S, Sriwiriyajan S (2003) Comparison of the pharmacodynamics of meropenem in healthy volunteers following administration by intermittent infusion or bolus injection. $\mathrm{J}$ Antimicrob Chemother 52(3):518-521. https://doi.org/10.1093/ jac/dkg378

9. Mattioli F, Fucile C, Del Bono V, Marini V, Parisini A, Molin A, Zuccoli ML, Milano G, Danesi R, Marchese A, Polillo M, Viscoli C, Pelosi P, Martelli A, Di Paolo A (2016) Population pharmacokinetics and probability of target attainment of meropenem in critically ill patients. Eur J Clin Pharmacol 72(7):839-848. https://doi. org/10.1007/s00228-016-2053-x

10. Crandon JL, Ariano RE, Zelenitsky SA, Nicasio AM, Kuti JL, Nicolau DP (2011) Optimization of meropenem dosage in the critically ill population based on renal function. Intensive Care Med 37(4):632-638. https://doi.org/10.1007/s00134-010-2105-0

11. Wiseman LR, Wagstaff AJ, Brogden RN, Bryson HM (1995) Meropenem. Drugs 50(1):73-101

12. Khwaja A (2012) KDIGO clinical practice guidelines for acute kidney injury. Nephron Clin Pract 120(4):c179-c184

13. Winter ME (2010) Basic clinical pharmacokinetics. Wolters Kluwer/Lippincott Williams \& Wilkins Health

14. Chambers HF, Eliopoulos GM, Gilbert DN, Saag MS (2016) The Sanford guide to antimicrobial therapy 2016. Antimicrobial Therapy

15. Elkhailli H, Niedergang S, Pompei D, Linger L, Leveque D, Jehl F (1996) High-performance liquid chromatographic assay for meropenem in serum. J Chromatogr B Biomed Sci Appl 686(1): 19-26. https://doi.org/10.1016/S0378-4347(96)00205-8

16. Madden A, Tsikoura T, Stott D (2012) The estimation of body height from ulna length in healthy adults from different ethnic groups. J Hum Nutr Diet 25(2):121-128
17. Kothekar AT, Divatia JV, Myatra SN, Patil A, Krishnamurthy MN, Maheshwarappa HM, Siddiqui SS, Gurjar M, Biswas S, Gota V (2020) Clinical pharmacokinetics of 3-h extended infusion of meropenem in adult patients with severe sepsis and septic shock: implications for empirical therapy against Gram-negative bacteria. Ann Intensive Care 10(1):4

18. Gonçalves-Pereira J, Póvoa P (2011) Antibiotics in critically ill patients: a systematic review of the pharmacokinetics of $\beta$-lactams. Crit Care 15(5):R206

19. Leroy A, Fillastre J, Borsa-Lebas F, Etienne I, Humbert G (1992) Pharmacokinetics of meropenem (ICI 194,660) and its metabolite (ICI 213,689) in healthy subjects and in patients with renal impairment. Antimicrob Agents Chemother 36(12):2794-2798

20. Kitzes-Cohen R, Farin D, Piva G, De Myttenaere-Bursztein SA (2002) Pharmacokinetics and pharmacodynamics of meropenem in critically ill patients. Int J Antimicrob Agents 19(2):105-110. https://doi.org/10.1016/S0924-8579(01)00474-5

21. Jaruratanasirikul S, Thengyai S, Wongpoowarak W, Wattanavijitkul T, Tangkitwanitjaroen K, Sukarnjanaset W, Jullangkoon M, Samaeng M (2015) Population pharmacokinetics and Monte Carlo dosing simulations of meropenem during the early phase of severe sepsis and septic shock in critically ill patients in intensive care units. Antimicrob Agents Chemother 59(6):29953001

22. Petersson J, Giske C, Eliasson E (2016) Standard dosing of piperacillin and meropenem fail to achieve adequate plasma concentrations in ICU patients. Acta Anaesthesiol Scand 60(10):1425-1436

23. Thalhammer F, Traunmüller F, Frass M, Hollenstein U, Locker G, Staudinger T, Burgmann H (2000) Continuous infusion versus intermittent administration of meropenem in critically ill patients: a pilot study. In: Critical Careed. BioMed Central, pp 1-2

Publisher's note Springer Nature remains neutral with regard to jurisdictional claims in published maps and institutional affiliations. 